\title{
Logistics and transport in industry 4.0: perspective for Ukraine
}

\author{
Igor Matyushenko ${ }^{1}{ }^{*}$, Sergiy Berenda ${ }^{1}$, Tatyana Shtal $^{2}$, and Larissa Grigorova-Berenda ${ }^{1}$ \\ ${ }^{1}$ V.N. Karazin Kharkiv National University (Kharkiv, Ukraine) \\ ${ }^{2}$ Simon Kuznets Kharkiv National University of Economics (Kharkiv, Ukraine)
}

\begin{abstract}
The elaboration of the fourth industrial revolution and the process of globalization of the world economy is sine qua non of the successful operation and transformation of logistics. The formation of Logistics 4.0 relies in particular on cutting-edge technologies and the digitalization of business processes. The complexity of the structure of world trade arouses interest to the complete range of logistics services provided within a single company. This logic of development requires the application of interdisciplinary approaches, combined with the efforts of engineers, researchers and those interested in the field of logistics.
\end{abstract}

\section{Introduction}

Comprehensive advanced manufacturing technologies of the Industry 4.0, including nine core technologies, such as cloud technologies, Internet of things, big data, modeling, system integration, cyber security, additive technologies, robotics or augmented reality, have a fundamental impact on how to manage and organize business and provide resources for it right here and now [1, 2]. These new technologies, which are enforced virtually ubiquitously and are kept with digital capabilities, increase the pace and scale of business change. At the same time, the development of the Industry 4.0 and the processes of digitalization of the world economy are impossible without the successful operation of logistics. The complexity of the structure of world trade arouses interest to the complete range of logistics services, which foregrounds the problem of formation of Logistics 4.0, which relies first and foremost on new technologies and the digitalization of business processes. This is confirmed in the works [3, 4].

This logic of development requires the application of interdisciplinary approaches, combined with the efforts of engineers, researchers and those interested in the field of logistics (in particular in the field of intelligent transport systems), which determines the relevance of the study.

\section{Presentation of basic material of the research}

\footnotetext{
* Corresponding author: imatyushenko@karazin.ua
} 
The transport and logistics industry is characterized by a relatively small number of large international companies and numerous regional and small companies. Such structure of the industry is due to the fact that there are few barriers to entry, but significant investments are required in order to grow to a certain size. The limited number of companies that are of sufficient size to use integrated information supply chain systems has led to the formation of a system environment that has a few standards and even fewer largescale specialized software and technologies.

Therefore, many large logistics companies have developed their own information systems, annually investing significant funds in supporting and upgrading these systems, thus forming an infrastructure of 3 PL, 4 PL and even 5 PL. Small players had to either use applications provided by local or niche software vendors or, as is often the case with small players in each industry, not use any applications or technologies outside the regular office of the program [5, p.12].

Leading Logistics Services Providers (LLPs), that are also called logistics providers (4PLs), have a vital role in the formation of a supply chain. They assume many of the same functions as Logistics Service Providers (3PLs), but have much wider responsibility, helping clients achieve their strategic goals.

Functioning as $4 \mathrm{PL}$, the logistics provider becomes a true partner with the client, working on creating an economic supply chain.

4PL usually manages each moving part within the customer supply chain and serves as the single point for contact with all parties. The LLP's role usually involves managing and analyzing large volumes of data, controlling transport management, managing other 3PLs and transport service providers, overseeing warehousing operations, or managing any other part of the supply chain.

Transparency is key to 4PL, which can also function as 3PL. They should actively cooperate with clients to demonstrate the containment and counterbalances they have introduced, for instance, the conclusion of confidentiality agreements that prohibit the exchange of information and data from other 3PLs and transportation [6, 7]. 5 PL providers of logistics services are formed around a business model using e-Business.

Each single logistics company in the supply chain manages its own ICT systems that connect to external systems through bi-directional communications (EDI). This information and communication technology management structure has benefited the software industry as well as the domain members with the financial and technical resources needed to use this business model [8].

In Ukraine, large technology companies in the IT sector are torn off from the domestic market. In fact, each of the "big IT four" - Luxoft, Infopulse, SoftServe, Eleks - has worked in area 4.0. But only Eleks started offering these solutions in Ukraine (Kernel project), all others work exclusively on Western markets. That is, neither these companies nor other key players of the IT industry pay attention to the development of the customer market in Ukraine.

Among the 100,000 programmers in the IT industry, 90\% work for export, of which $70 \%$ are outsourced (IDC-Ukraine data from 2017). And only 5\% of the IT industry is involved in industrial applications [9].

Moreover, the latest data of 2019 indicate an unprecedented rise in this sector of the economy, in the city of Kharkiv alone there are officially employed about 30,000 IT specialists and another 10,000 are working on free freelancing serving export markets. Thus, it can be argued that there are IT opportunities for creating the appropriate infrastructure for 4PL and 5 PL operators in Ukraine. However, at the moment, only foreign 4PL operators are working in Ukraine. And the general engineering infrastructure and business environment shows that the creation of national $4 \mathrm{PL}$ and 5PL operators is possible only in close cooperation with leading foreign companies. 
However, the positive development trends of this market in Ukraine and in the world overlap. In Ukraine, there is a rapid growth in the development of 3 PL operators and their revenues, as a response to new opportunities offered by Internet commerce in the area of cost reduction, and as a result, a decrease in prices. Under conditions of low solvency in Ukraine, this factor is a key driver of the development of the entire market.

On the background of the appearance of 5 PL logistic operators, and the improvement of business models of 1PL-4PL providers, the crucial task for the further development of logistics services is to create the appropriate infrastructure. The European Commission has adopted regulations aimed at accelerating the implementation of intelligent transport systems on the European road system (C-ITS). These systems should improve traffic flow and safety.

The new technology will allow vehicles to "talk" to each other, with road infrastructure and other road users - for example, on dangerous situations, road works and time of traffic lights, making road transport safer, cleaner and more efficient, the so-called V2V approach (vehicle to vehicle). This solution gives car makers, road operators and others this longawaited legal certainty required to start a large-scale deployment of C-ITS services in Europe, remaining open to new technologies and market development. The first C-Roads tests (intelligent roads with the C-ITS system) were conducted within the framework of the pilot program in 2018. Cars from France and Portugal easily "communicate" with the "intelligent" highway in Austria. At the moment, car makers such as Hyundai, Opel, Honda, Volkswagen, Renault, Volvo Trucks and Fiat have committed to equip their cars with C-ITS since 2019 [10, 11].

Therefore, it is quite logical to ask how the logic of Industry 4.0 and the Logistics 4.0 paradigm can conjugate, where its important part is its dependence on the past, the socalled "path depends" and how it is bound to affect future development.

There are five main elements of Logistics 4.0:

1. Transparency. One of the most important aspects of modern logistics is the increase in transparency resulting from the enhanced digitalization of the entire supply chain, which has the potential to make modern logistics much more efficient and comprehensive.

2. Smart Containers and Pallets. As for smart ports, there are many other "smart" versions of traditional logistics components that change the way the goods move from suppliers to customers.

3. Adaption to IoT (Internet of Things). When it comes to smart containers, pallets, vehicles, ports, etc., the question remains: how to maximize the ability of a person to obtain significant data from different adherent point of the value chain and turn these data into valuable, integrated ideas. In Industry 4.0, this role is filled by IoT devices that are installed in production facilities and warehouses.

4. Integration with Industry 4.0. One of the most important aspects of logistics 4.0 is its ability to integrate easily with Industry 4.0 systems, creating symbiotic, synergistic relationships between manufacturers and shippers. Despite the fact that the full implications of the relationship between logistics digitalization and intelligent manufacturing processes remain unresolved, it is clear that the benefits of such integration are much greater.

5. Collection of analytics. So far, many important things have been done to collect data in these new logistics frameworks, but the real value of this data is not limited to simplifying manual planning. Most likely, completing success in the area of transparency, visibility and data collection using sensors, NFC tags and RFID chips is the use of advanced analytical work. By providing a large amount of information to forecasting and planning algorithms, modern logistics providers can improve their forecast of demand and shipping, identifying potential loss zones or possible improvement of the market. This helps lay the foundations for a smoother version of the supply chain management, which is less prone to risks, failures and opacity [12]. 


\section{Conclusions resulting from the study}

Consequently, we can draw the following conclusions: in the leading economies of the world there is a synchronous and integrated development of Industry 4.0 and Logistics 4.0. Modern logistics services in the EU countries are commercially successful in exploiting the latest approaches, such as 5PL.

Ukrainian companies are only fragmentary ready to implement the principles of industry 4.0 in logistics, so the competitive struggle for this highly profitable market is losing by them. Meanwhile, this technological gap is only increasing. Therefore, the prospects for the emergence of 5PL operators and the corresponding market for such services in the next 3 years in Ukraine cannot be expected. The focus of further research is on the management of interdisciplinary approach, which enables the formation of competitive advantages of modern logistics services based on a combination of engineering, business and research experience.

\section{Refernces}

1. I. Matyushenko Prospects for the development of convergent technologies in the countries of the world and Ukraine for solving global problems: a monograph. Kharkiv: FB Liborkina LM, 448 p. (2017)

2. K. Shvab The Fourth Industrial Revolution / Trans. from English Moscow: Publishing house "E", 2017. 208 p.

3. K. Witkowski "Internet of things, big data, industry 4.0-innovative solutions in logistics and supply chains management." Procedia Engineering 182 (2017): 763-769.

4. E. Hofmann, M. Rüsch. "Industry 4.0 and the current status as well as future prospects on logistics." Computers in Industry 89 (2017): 23-34.

5. Information Systems for Interconnected Logistics. Research \& Innovation Roadmap. https://www.etp-logistics.eu/wp-content/uploads/2015/08/W36mayo-kopie.pdf (2019). Accessed 6 Feb 2019

6. 4PL VS. 3PL. https://www.penskelogistics.com/solutions/supply-chainmanagement/lead-logistics-provider/4pl-vs-3pl-differences/ (2019). Accessed $10 \mathrm{Feb}$ 2019

7. A hybrid data analytical methodology for 3PL transport provider evaluation using fuzzy multi-criteria decision making. https://doi.org/10.1080/00207543.2015.1022266 (2019). Accessed 22 Feb 2019

8. 5 Key Elements of Logistics 4.0. https://blog.flexis.com/5-key-elements-of-logistics-4.0 (2019). Accessed 6 Feb 2019

9. National strategy of Industry 4.0 Project for the Cabinet of Ministers of https://drive.google.com/file/d/1VU0LPVXUs6rUTjuct69Dptek8tqkNIsd/view (2019). Accessed 2 Mar 2019

10. Brussels: new vehicles must communicate with the road infrastructure. https://trans.info (2019). Accessed 12 Mar 2019

11. Information Systems for Interconnected Logistics. https://www.etp-logistics.eu/wpcontent/uploads/2015/08/W36mayo-kopie.pdf (2019). Accessed 1 Feb 2019

12. S. Berenda, N. Zaporozhsky Use of international fullfilment-warehouses in the formation of supply chains // "Current state and prospects of economy, accounting, finance and management in Ukraine and the world": a collection of abstracts of the International Scientific and Practical Conference, (November 14, 2017 in Poltava, Ukraine) - Poltava: TSFEND, pp. 249-250. (2017) 